\title{
PENGARUH BOPO, FDR DAN NPF TERHADAP PROFITABILITAS (ROA) PADA BANK SYARIAH PERIODE 2009-2019
}

\section{Ahmad Fauzul Hakim Hasibuan ${ }^{1}$}

Falahuddin ${ }^{2}$

Hail Ulva ${ }^{3}$

${ }^{1}$ Islamic Economics Department, Faculty of Economics and Business, University of Malikussaleh

${ }^{2}$ Islamic Economics Department, Faculty of Economics and Business, University of Malikussaleh

${ }^{3}$ Islamic Economics Department, Faculty of Economics and Business, University of Malikussaleh

${ }^{1}$ fauzulhakim@unimal.ac.id

fallahudiin@unimal.ac.id

33hail160440084@mhs.unimal.ac.id

\section{ARTICLE HISTORY}

Received:

10 April 2021

Revised

15 April 2021

Accepted:

24 Mei 2021

Online available:

19 Juni 2021

Keywords (Calibri 10):

BOPO, FDR, NPF, ROA, VAR

*Correspondence:

Name: hailulva

E-mail:

hail160440084@mhs.unimal.ac.id

\begin{abstract}
This study aims to determine the effect of operational costs on the operational income, financing to deposit ratio, and nonperforming financing to profitability (ROA) in Islamic banks during 2009-2019. The data used in this study are secondary data sourced from Islamic banking financial statements accessed on the official website of the Financial Services Authority with monthly data from January 2009 to December 2019. This study used is a quantitative approach with VAR (Vector Auto-Regressive) analysis, consisting of stationarity test, optimal lag test, VAR model stability test, Granger causality test, impulse response function test, and variance decomposition test. Based on the results of this study, it concludes that NPF is more dominant in influencing profitability (ROA) in the short and long term. The results of the Granger causality test show that all variables have a causal relationship with each other, meaning that each variable has a causal relationship with each other and has a two-way relationship with other variables. The variables used in this study are BOPO, FDR, NPF. It is hoped that the next researcher can use more not only Islamic bank financial performance variables but also income, inflation, interest rates, and investment variables that are included as determinants of ROA levels in Islamic banking in Indonesia.
\end{abstract}




\section{PENDAHULUAN}

Laju perekonomian masyarakat indonesia kian meningkat saat ini uang menjadi alat yang sangat penting bagi kebutuhan manusia. Perbankan sebagai bagian dari perekonomian memiliki peran penting dalam pertumbuhan ekonomi. Di indonesia, terdapat dua jenis perbankan yaitu perbankan konvensional dan perbankan syariah. Sama halnya dengan perbankan konvensional, perbankan syariah juga memilki fungsi yang sama yaitu sebagai lembaga perantara keuangan dalam menghimpun dan menyalurkan dana kepada nasabah (Timothy:2018).

Berikut adalah Kondisi Rasio Keuangan ROA, BOPO, FDR dan NPF Pada Bank Syariah Periode 2009-2019.

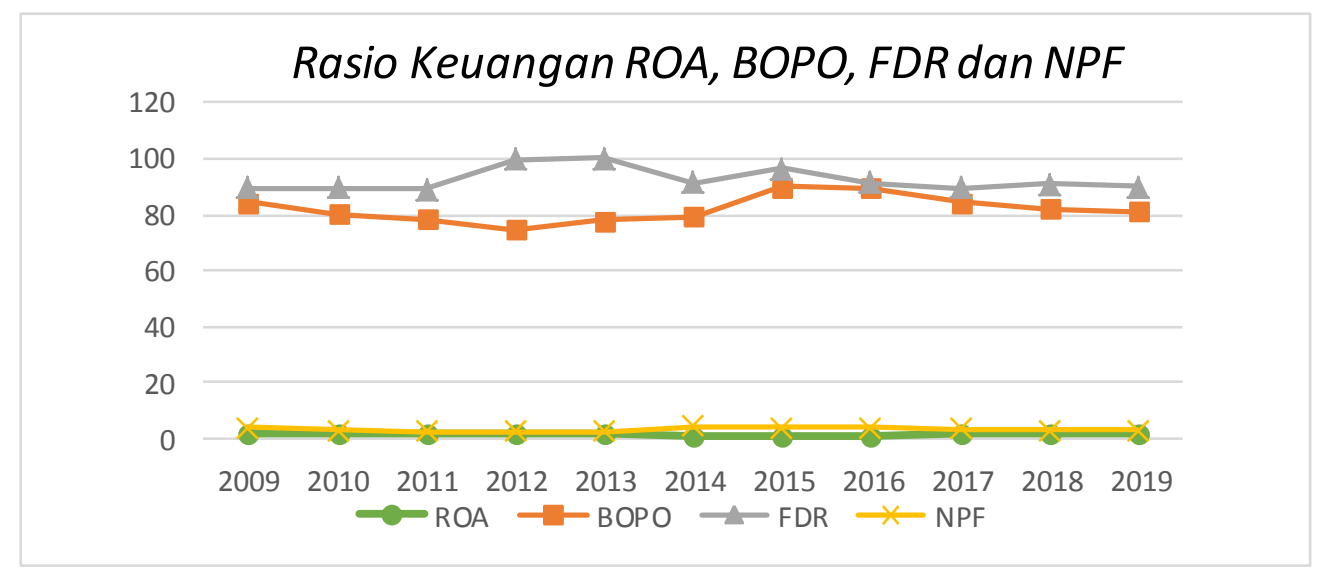

Sumber : Statistik Perbankan Syariah (www.ojk.go.id), diolah 2020

Perbankan syariah mengalami perubahan pada kinerja keuangan setiap tahun yang digambarkan melalui rasio keuangan. Dapat dilihat pada grafik diatas pergerakan rasio keuangan perbankan periode tahun 2009 hingga 2019 adanya lonjakan dan penurunan yang tidak konsisten dari variabel ROA, BOPO, FDR maupun NPF. Penelitian ini terkait tentang upaya perbaikan kinerja untuk meningkatkan profitabilitas perbakan syariah di Indonesia agar perbankan dengan prinsip syariah tetap sehat dan efisien, sehingga perlu diketahui faktor-faktor yang mempengaruhi indikator tersebut agar dapat diambil langkah yang tepat guna perbaikan kinerja untuk meningkatkan profitabilitas perbankan syariah dan perlu dilakukan penelitian selanjutnya, maka penulis tertarik melakukan penelitian lebih lanjut mengenai Pengaruh BOPO, FDR dan NPF Terhadap Profitabilitas (ROA) Pada Bank Syariah Periode 2009-2019.

\section{TINJAUAN PUSTAKA}

\section{Laporan Keuangan Bank Syariah}

Setiap perusahaan, baik bank maupun nonbank pada suatu waktu (periode tertentu) akan melaporkan semua kegiatan keuangannya. Laporan keuanan ini bertujuan memberikan informasi keuangan perusahaan, baik kepada pemilik, manajemen, maupun pihak luar yang berkepentingan terhadap laporan tersebut. 
Laporan keuangan bank menunjukkan kondisi keuangan bank secara keseluruhan. Dari laporan ini akan terbaca bagaimana kondisi bank yang sesungguhnya, termasuk kelemahan dan kekuatan yang dimiliki. Laporan ini juga menunjukkan kinerja manajemen bank selama satu periode.

\section{Profitabilitas}

Gitman dan Zutter (2012) mengatakan profitabilitas adalah kemampuan suatu perusahaan dalam menghasilkan profit. Perusahaan yang memiliki profit yang baik akan menjadi incaran para investor. Profitabilitas adalah pertahanan yang utama dalam bank terhadap kerugian yang tidak terduga, seperti memperkuat posisi modal dan meningkatkan profitabilitas masa depan melalui investasi laba ditahan (Annisa:2015).

\section{Return On Asset (ROA)}

Profitabilitas atau Return On Asset (ROA) ini merupakan rasio untuk menilai kemampuan perusahaan dalam mencari keuntungan. Penilaian kinerja keuangan bank yang dapat dinilai oleh pendekatan analisis rasio keuangan inilah juga memberikan ukuran tingkat efektivitas manajemen suatu perusahaan. Semakin besar Return On Asset (ROA) menunjukkan kinerja perusahaan semakin baik.

Dari penjelasan diatas dapat diartikan bahwa Return On Asset (ROA) sebagai kemampuan perusahaan atau bank untuk menghasilkan keuntungan atau laba selama periode tertentu yang menunjukkan perbandingan antara laba sebelum pajak dengan total aset bank (Lemiyana:2016).

\section{Biaya Operasional terhadap Pendapatan Operasional (BOPO)}

Rasio Biaya Operasional terhadap Pendapatan Operasional (BOPO) sering disebut rasio efisiensi yang digunakan untuk mengukur kemampuan manajemen bank dalam mengendalikan biaya operasional terhadap pendapatan operasional.

BOPO memiliki pengaruh terhadap profitabilitas bank karena menunjukkan seberapa besar bank dapat melakukan efisiensi biaya yang dikeluarkan (Dendawijaya, 2003:112).

\section{Financing to Deposit Ratio (FDR)}

Rasio Financing to Deposit Ratio (FDR) digunakan untuk mengukur kemampuan bank dalam memenuhi kewajiban-kewajiban jangka pendeknya atau kewajiban yang sudah jatuh tempo. FDR merupakan perbandingan antara pembiayaan yang diberikan oleh bank dengan dana pihak ketiga yang berhasil dikerahkan oleh bank (Suhartatik dan Kusumaningtias, 2013).

\section{Non Performing Financing (NPF)}

Non Performing Financing (NPF) adalah rasio yang muncul akibat adanya pembiayaan bermasalah atau risiko pembiayaan pada bank syariah. Tujuan dari rasio tersebut adalah untuk mengukur tingkat permasalahan pada pembiayaan yang dihadapi 
oleh bank. Non Performing Financing (NPF) adalah pembiayaan yang dikategorikan dalam kolektabilitas kurang lancar, diragukan dan macet.

\section{PENELITIAN TERDAHULU}

Lemiyana dan Erdah Litriani (2016) menganalisis pengaruh NPF, FDR, BOPO terhadap Return On Asset (ROA) Pada Bank Umum Syariah. Bentuk penelitian yang digunakan adalah penelitian asosiatif kausal dengan pendekatan kuantitatif. Jenis data di dalam penelitian ini adalah data panel dan metode analisis datanya yaitu regresi data panel. Hasil penelitian ini menemukan bahwa secara parsial variabel NPF dan FDR tidak ada pengaruh terhadap Return On Asset (ROA). Sedangkan Variabel BOPO berpengaruh negatif terhadap Return On Asset (ROA). Secara simultan NPF, FDR, BOPO, tidak ada pengaruh signifikan terhadap Return On Asset (ROA).

Sani Noor Rohman dan Karsinah (2016) Analisis Determinan Pangsa Pasar Bank Syariah dengan Kinerja Bank Syariah di Indonesia Periode 2011-2016. Analisis yang digunakan menggunakan metode VAR (Vector Auto Regression) yang secara teoritis tidak terjadi hubungan antar variabel dengan model VAR In Difference. Hasil analisis Impulse Respons Function (IRF) terhadap kinerja bank syariah menunjukkan Pangsa pasar bank syariah merespon positif terhadap varaiabel BOPO, CAR, ROA dan FDR, sedangkan variabel NPF merespon negatif. Secara keseluruhan diperoleh hasil bahwa variabel ROA memberikan kontribusi yang lebih besar dalam jangka menengah dan jangka panjang menjelaskan variabilitas Pangsa Pasar bila dibandingkan dengan BOPO, ROA, CAR, FDR, dan NPF.

\section{DESAIN PENELITIAN}

Penelitian ini menggunakan metode kuantitatif. Teknik penarikan sampel dalam penelitian ini adalah dengan menggunakan metode purposive sampling, dimana metode ini merupakan sampel yang diambil dengan berbagai pertimbangan. Adapun sampelnya adalah data Bank Syariah yang laporan keuangannya sudah teraudit BI, Bank Syariah di Indonesia yang memiliki data yang dibutuhkan terkait pengukuran variabel-variabel yang digunakan untuk penelitian selama periode 2009-2019. Bank Syariah yang telah mempublikasi Laporan keuangan secara kontinyu dan lengkap setiap bulannya oleh Otoritas Jasa Keuangan (OJK). Sedangkan untuk data penelitian merupakan data time series yaitu data yang dikumpulkan dari waktu ke waktu pada suatu obyek dengan tujuan menggambarkan perkembangannya.

\section{HIPOTESIS PENELITIAN}

Adapun hipotesis yang dirumuskan dalam penulisan ini adalah sebagai berikut:

$\mathrm{H}_{0}$ : Tidak ada pengaruh BOPO, FDR dan NPF secara parsial maupun bersama-sama (simultan) terhadap profitabilitas (ROA) pada Bank Syariah.

$\mathrm{H}_{1}$ : Ada pengaruh BOPO, FDR dan NPF secara parsial maupun bersama-sama (simultan) terhadap profitabilitas (ROA) pada Bank Syariah. 


\section{METODE PENELITIAN}

Dalam penelitian ini Metode analisis data dalam penelitian ini menggunakan model analisis Vector Autoregression (VAR). Vector Autoregression (VAR) merupakan salah satu metode time series yang sering digunakan dalam penelitian, terutama dalam bidang ekonomi. Metodologi VAR pertama kali dikemukakan oleh Sims (1980). Adapun tahapan dalam melakukan analisis VAR/VECM adalah uji stasioneritas, penentuan lag optimal, uji kointegrasi, estimasi model VAR, uji Kausalitas Granger, uji IRF, dan uji Variance Decomposition. Untuk lebih jelasnya dapat dilihat pada gambar berikut.

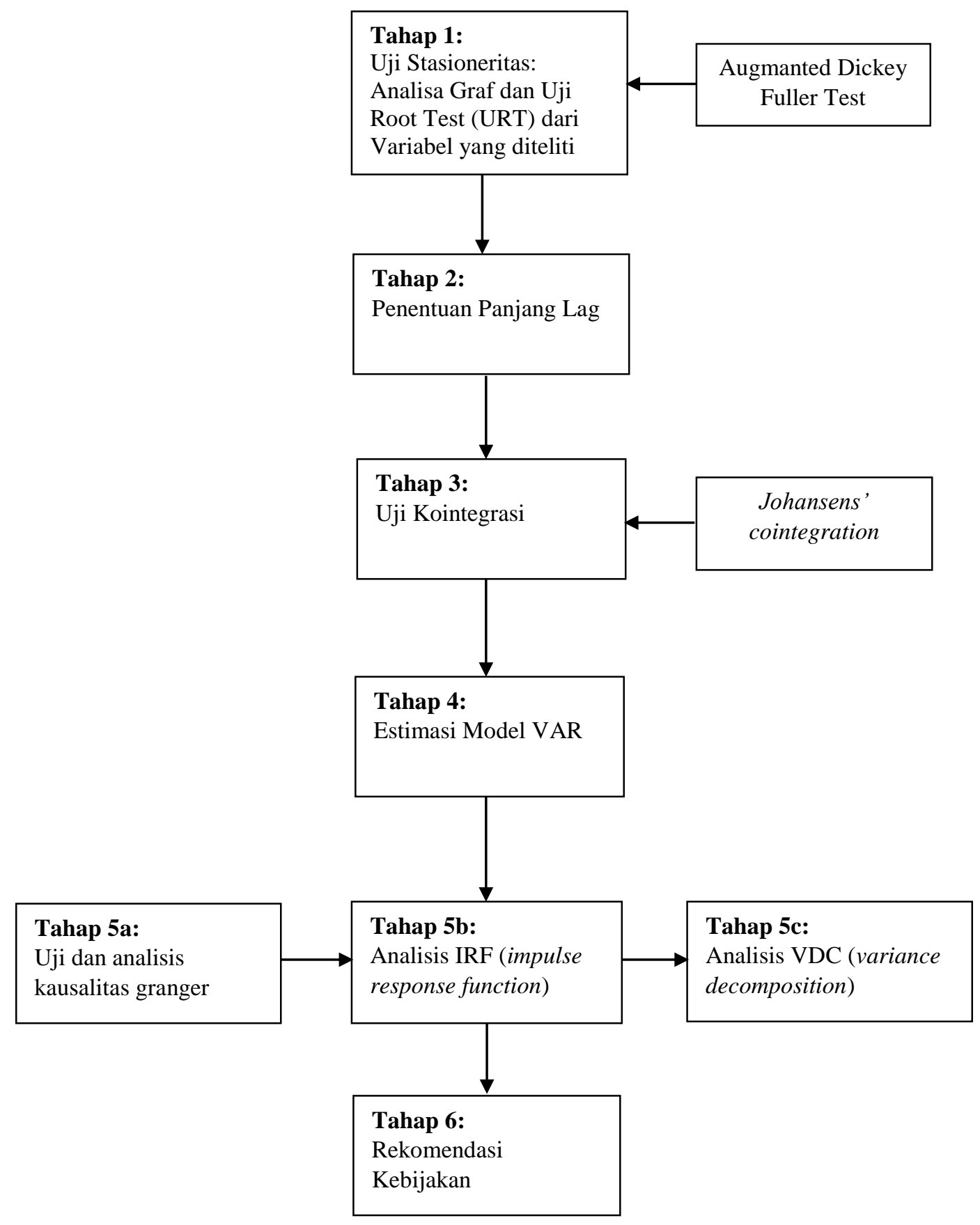




\section{HASIL PENELITIAN DAN PEMBAHASAN}

1. Hasil Uji Stasioneritas

\begin{tabular}{c|c|c|c|c|c}
\hline Variabel & $\begin{array}{c}\text { Unit Root } \\
\text { Test in }\end{array}$ & $\begin{array}{c}\text { ADF Test } \\
\text { Statistic }\end{array}$ & $\begin{array}{c}\text { Critical } \\
\text { Value 5\% }\end{array}$ & Prob & Keterangan \\
\hline ROA & Level & -11.41021 & -2.883579 & 0.0000 & Stasioner \\
\hline BOPO & Level & -2.935321 & -2.883753 & 0.0441 & Stasioner \\
\hline FDR & Level & -8.048160 & -2.883753 & 0.0000 & Stasioner \\
\hline NPF & Level & -1.892146 & -2.883930 & 0.3352 & Stasioner \\
\hline
\end{tabular}

Sumber: Hasil Penelitian (diolah), 2020

Hasil stasioneritas menunjukkan bahwa variabel ROA, BOPO, FDR dan NPF telah stasioner ditingkat level pada taraf nyata $5 \%$. Hal ini dikarenakan nilai absolute ADF variabel-variabel tersebut lebih kecil dibanding dengan nilai kritis $5 \%$.

\section{Hasil Uji Lag Optimal}

\begin{tabular}{c|c|c|c|c|c|c}
\hline Lag & LogL & LR & FPE & AIC & SC & HQ \\
\hline 0 & -1362.227 & NA & 43669.88 & 22.03592 & 22.12690 & 22.07288 \\
1 & -1111.406 & 481.4144 & 989.4537 & 18.24849 & $18.70337^{*}$ & 18.43327 \\
2 & -1086.059 & 47.01476 & $851.7060^{*}$ & $\mathbf{1 8 . 0 9 7 7 3 *}$ & 18.91652 & $18.43034^{*}$ \\
3 & -1078.607 & 13.34128 & 979.6394 & 18.23560 & 19.41830 & 18.71604 \\
4 & -1064.344 & 24.61555 & 1011.363 & 18.26361 & 19.81022 & 18.89188 \\
5 & -1056.893 & 12.37777 & 1168.150 & 18.40150 & 20.31202 & 19.17760 \\
6 & -1043.765 & 20.96330 & 1234.860 & 18.44782 & 20.72224 & 19.37174 \\
7 & -1019.793 & $36.73160^{*}$ & 1099.931 & 18.31923 & 20.95756 & 19.39099 \\
8 & -1011.677 & 11.91093 & 1270.816 & 18.44641 & 21.44864 & 19.66599 \\
\hline
\end{tabular}

Sumber: Hasil Penelitian (diolah), 2020

Berdasarkan uji lag optimal menggunakan kriteria SIC, maka penulis menggunakan lag optimal adalah 2. Setelah diakumulasikan maka jumlah bintang terbanyak pada lag 2. Seperti yang tertera pada tabel yang telah penulis tampilkan diatas, dimana kriteria kecil dari AIC adalah 18.09773 yang terletak pada lag 2.

\section{Hasil Uji Stabilitas Model VAR}

\begin{tabular}{cl}
\hline \hline Root & Modulus \\
\hline \hline 0.937707 & 0.937707 \\
0.865454 & 0.865454 \\
$-0.000171-0.398748 \mathrm{i}$ & 0.398748 \\
$-0.000171+0.398748 \mathrm{i}$ & 0.398748 \\
$-0.362399-0.126232 \mathrm{i}$ & 0.383754 \\
$-0.362399+0.126232 \mathrm{i}$ & 0.383754 \\
$-0.012058-0.144625 \mathrm{i}$ & 0.145127 \\
$-0.012058+0.144625 \mathrm{i}$ & 0.145127 \\
\hline \hline
\end{tabular}

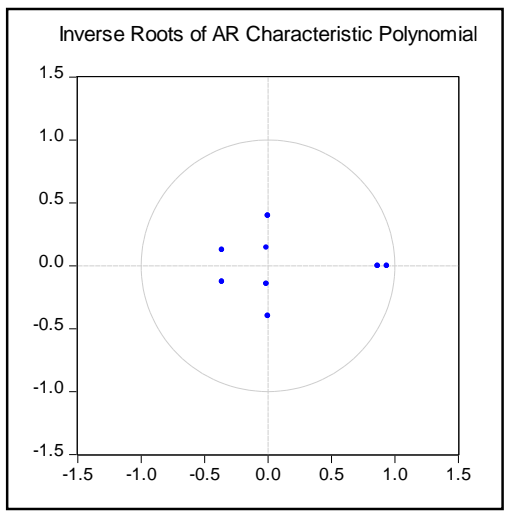

Sumber: Hasil Penelitian (diolah), 2020 
Dari hasil pengujian stabilitas VAR menunjukkan bahwa tidak ada akar unit yang terlihat dari tabel dimana roots memiliki modulus lebih kecil dari 1. Dan hal ini juga didukung dari gambar titik invers roots of $A R$ Characteristic polynomial yang kesemua variabel berada dalam lingkaran. Maka sudah jelas hasil pengujian ini menunjukkan bahwa model VAR sudah stabil atau stasioner.

\section{Hasil Uji Kausalitas}

\begin{tabular}{|c|c|c|c|}
\hline Null Hypothesis: & Obs & F-Statistic & Prob. \\
\hline BOPO does not Granger Cause ROA & 130 & 0.35157 & 0.7043 \\
\hline ROA does not Granger Cause BOPO & & 0.49564 & 0.6104 \\
\hline FDR does not Granger Cause ROA & 130 & 0.00437 & 0.9956 \\
\hline ROA does not Granger Cause FDR & & 0.00171 & 0.9983 \\
\hline NPF does not Granger Cause ROA & 130 & 0.91108 & 0.4047 \\
\hline ROA does not Granger Cause NPF & & 0.03985 & 0.9609 \\
\hline FDR does not Granger Cause BOPO & 130 & 0.00050 & 0.9995 \\
\hline BOPO does not Granger Cause FDR & & 4.06508 & 0.0195 \\
\hline NPF does not Granger Cause BOPO & 130 & 2.57479 & 0.0802 \\
\hline BOPO does not Granger Cause NPF & & 0.02343 & 0.9768 \\
\hline NPF does not Granger Cause FDR & 130 & 1.80973 & 0.1680 \\
\hline FDR does not Granger Cause NPF & & 3.42054 & 0.0358 \\
\hline
\end{tabular}

Sumber: Hasil Penelitian (diolah), 2020

Dari table hasil uji kausalitas diatas menunjukkan bahwa:

$H_{0}$ : BOPO tidak ada hubungan kausalitas dengan ROA

$H_{1}$ : BOPO memiliki hubungan kausalitas dengan ROA

Pengujian granger kausalitas untuk persamaan yang pertama $\left(\beta_{11}=0\right.$ dan $\beta_{12}=$ 0 ) terlihat bahwa tidak terjadinya granger causality antara BOPO dan ROA. Menunjukkan F-statistik $=0,35157$ dan probabilitas $=0,5891$. maka $H_{0}$ diterima yang artinya BOPO tidak memiliki hubungan kausalitas dengan ROA.

Dst.

\section{Hasil Uji Impulse Response Function (IRF)}

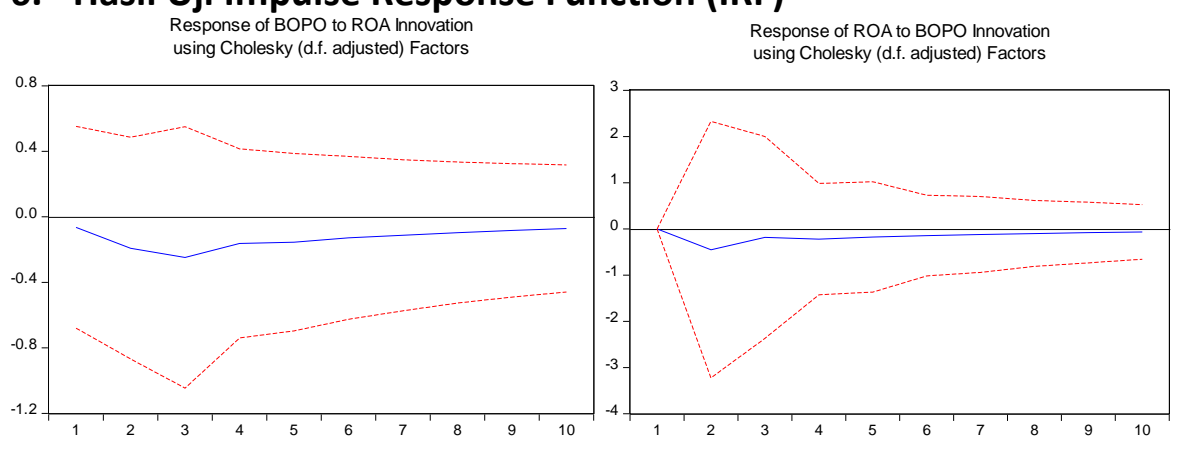

Sumber: Hasil Penelitian (diolah), 2020 
Dari gambar diatas dilihat bahwa variabel Return on Asset (ROA) dalam merespon adanya shock dari variabel Biaya Operasional terhadap Pendapatan Operasional (BOPO) pada panel Response of BOPO to ROA. Dimana BOPO merespon negatif dari guncangan ROA tetapi semakin seimbang sampai periode ke-10. Sedangkan pada panel Response of $R O A$ to BOPO terlihat bahwa ROA juga merespon negatif guncangan BOPO yang semakin menjauh dari titik keseimbangan pada periode ke-2. Namun pada akhirnya ROA dalam merespon guncangan dari BOPO semakin seimbang.

Dst.

\section{Hasil Uji Variance Decomposition (VD)}

\section{Variance Decomposition BOPO, FDR dan NPF terhadap ROA} Variance Decomposition of ROA:

\begin{tabular}{cccccc} 
Period & S.E. & ROA & BOPO & FDR & NPF \\
\hline \hline 1 & 15.93466 & 100.0000 & 0.000000 & 0.000000 & 0.000000 \\
2 & 15.95392 & 99.79622 & 0.079698 & 0.002038 & 0.122040 \\
3 & 15.96580 & 99.68176 & 0.092974 & 0.004449 & 0.220818 \\
4 & 15.97552 & 99.56149 & 0.112346 & 0.004448 & 0.321714 \\
5 & 15.98355 & 99.46177 & 0.124348 & 0.004455 & 0.409431 \\
6 & 15.99116 & 99.36740 & 0.132598 & 0.004465 & 0.495540 \\
7 & 15.99807 & 99.28169 & 0.138197 & 0.004476 & 0.575633 \\
8 & 16.00440 & 99.20331 & 0.141974 & 0.004473 & 0.650239 \\
9 & 16.01017 & 99.13190 & 0.144501 & 0.004470 & 0.719125 \\
10 & 16.01543 & 99.06687 & 0.146128 & 0.004468 & 0.782533 \\
\hline \hline
\end{tabular}

Sumber: Hasil Penelitian (diolah), 2020

Dari hasil uji variance decompositin di atas dapat dilihat bahwa variasi Return on Asset (ROA) dipengaruhi oleh Return on Asset (ROA) itu sendiri pada periode pertama $100 \%$. Sedangkan periode kedua variasi nilai prediksi ROA 99,79\%. Dan sisanya disumbangkan oleh variabel lain yaitu BOPO 0,07\%, FDR 0,002\% dan NPF 0,12\%. Variance terbesar adalah NPF dengan nilai 0,78\% pada periode ke-10. Dan FDR memiliki variance terkecil terhadap Return on Asset (ROA).

Variance Decomposition ROA, FDR dan NPF terhadap BOPO Variance Decomposition of BOPO:

\begin{tabular}{cccccc} 
Period & S.E. & ROA & BOPO & FDR & NPF \\
\hline \hline 1 & 3.111110 & 0.042340 & 99.95766 & 0.000000 & 0.000000 \\
2 & 3.475443 & 0.339479 & 99.13141 & 0.209655 & 0.319455 \\
3 & 3.859677 & 0.687833 & 98.29426 & 0.446434 & 0.571469 \\
4 & 4.081532 & 0.773961 & 97.81240 & 0.626835 & 0.786804 \\
5 & 4.255186 & 0.844951 & 97.17398 & 0.640047 & 1.341024 \\
6 & 4.384134 & 0.882193 & 96.43022 & 0.667118 & 2.020468 \\
7 & 4.484884 & 0.906594 & 95.52965 & 0.677118 & 2.886639 \\
8 & 4.566264 & 0.919201 & 94.54121 & 0.680298 & 3.859293 \\
9 & 4.633618 & 0.924765 & 93.48919 & 0.677680 & 4.908368 \\
10 & 4.690910 & 0.925441 & 92.40394 & 0.672396 & 5.998226 \\
\hline \hline
\end{tabular}

Sumber: Hasil Penelitian (diolah), 2020 
Dari hasil uji variance decomposition di atas dapat dilihat bahwa variasi BOPO dipengeruhi oleh BOPO itu sendiri pada periode pertama sebesar 99,95\% dan ROA mempengaruhi BOPO sebesar 0,04\%. Pada periode kedua variasi nilai prediksi BOPO sebesar 99,13\% dan sisanya disumbangkan oleh variabel lain yaitu ROA 0,33\%, FDR $0,20 \%$ dan NPF $0,31 \%$. Variance terbesar adalah NPF yaitu mencapai $5,99 \%$ pada periode ke-10. Dan FDR memiliki variance terkecil terhadap BOPO.

Variance Decomposition ROA, BOPO dan NPF terhadap FDR Variance Decomposition of FDR:

\begin{tabular}{cccccc} 
Period & S.E. & ROA & BOPO & FDR & NPF \\
\hline \hline 1 & 839.9925 & 0.004210 & 0.082690 & 99.91310 & 0.000000 \\
2 & 848.2213 & 0.005287 & 0.278556 & 99.55076 & 0.165402 \\
3 & 876.4291 & 0.006907 & 4.372552 & 94.05162 & 1.568916 \\
4 & 882.9647 & 0.029780 & 4.998358 & 92.72965 & 2.242213 \\
5 & 887.7699 & 0.048305 & 5.647027 & 91.81561 & 2.489060 \\
6 & 891.2872 & 0.054257 & 6.113757 & 91.10028 & 2.731708 \\
7 & 894.0286 & 0.060187 & 6.495608 & 90.54514 & 2.899065 \\
8 & 895.9847 & 0.064687 & 6.762488 & 90.15662 & 3.016206 \\
9 & 897.3897 & 0.068098 & 6.959286 & 89.87907 & 3.093544 \\
10 & 898.4221 & 0.070538 & 7.106840 & 89.67561 & 3.147012 \\
\hline \hline
\end{tabular}

Sumber: Hasil Penelitian (diolah), 2020

Dari hasil uji variance decomposition di atas dapat dilihat bahwa variasi FDR dipengaruhi oleh FDR itu sendiri pada periode pertama sebesar 99,91\%. ROA mempengaruhi FDR sebesar 0,004\% dan BOPO sebesar 0,08\%. Sedangkan pada periode kedua variasi nilai prediksi FDR sebesar 99,55\% dan sisanya disumbangkan oleh variabel lain yaitu ROA 0,005\%, BOPO 0,27\% dan NPF sebesar 0,16\%. Variance terbesar adalah BOPO yaitu mencapai $7,10 \%$ pada periode ke-10 dan ROA memiliki variance terkecil terhadap FDR.

\section{Variance Decomposition ROA, BOPO dan FDR terhadap NPF}

Variance Decomposition of NPF:

\begin{tabular}{cccccc} 
Period & S.E. & ROA & BOPO & FDR & NPF \\
\hline \hline 1 & 0.323266 & $1.95 \mathrm{E}-05$ & 0.119488 & 0.579889 & 99.30060 \\
2 & 0.398982 & 0.007962 & 0.229348 & 1.795136 & 97.96755 \\
3 & 0.460706 & 0.016067 & 0.244227 & 1.721344 & 98.01836 \\
4 & 0.506560 & 0.016117 & 0.320658 & 1.431666 & 98.23156 \\
5 & 0.545594 & 0.016895 & 0.284924 & 1.235703 & 98.46248 \\
6 & 0.578587 & 0.016561 & 0.261955 & 1.101953 & 98.61953 \\
7 & 0.606460 & 0.015836 & 0.239872 & 1.008129 & 98.73616 \\
8 & 0.630439 & 0.015206 & 0.222090 & 0.937210 & 98.82549 \\
9 & 0.651137 & 0.014577 & 0.208475 & 0.882144 & 98.89480 \\
10 & 0.669102 & 0.014000 & 0.198639 & 0.838837 & 98.94852 \\
\hline \hline
\end{tabular}

Sumber: Hasil Penelitian (diolah), 2020 
Dari hasil uji variance decomposition di atas dapat dilihat bahwa variasi NPF dipengaruhi oleh NPF itu sendiri pada periode pertama sebesar 99,30\%, ROA 1,95\%, BOPO 0,11\% dan FDR 0,57\%. Pada periode kedua variasi nilai prediksi NPF sebesar $97,96 \%$ dan sisanya disumbangkan oleh variabel lain yaitu ROA 0,007\%, BOPO 0,22\% dan FDR sebesar $1,79 \%$. Variance terbesar adalah FDR yaitu mencapai $0,83 \%$ pada periode ke-10 dan ROA memiliki variance terkecil terhadap NPF.

\section{KESIMPULAN DAN REKOMENDASI}

Berdasarkan hasil penelitian dan pembahasan, maka dapat ditarik kesimpulan sebagai berikut:

1. BOPO memiliki kemampuan dalam mempengaruhi Return on Asset (ROA) sebesar $0,14 \%$

2. FDR memiliki kemampuan dalam mempengaruhi Return on Asset (ROA) sebesar $0,004 \%$

3. NPF memiliki kemampuan dalam mempengaruhi Return on Asset (ROA) sebesar $0,78 \%$

Dari hasil penelitian diatas dapat dilihat bahwa Return on Asset (ROA) dalam perkembangannya lebih dipengaruhi oleh NPF yakni sebesar 0,78\% dibandingkan dengan FDR yakni sebesar $0,004 \%$. Hal ini diharapkan bagi pihak bank untuk menjaga kestabilan FDR agar semakin efektif dalam menyalurkan pembiayaannya sehingga pendapatan yang diperoleh bank juga semakin meningkat dan juga tetap mempertahankan rasio-rasio keuangan lainnya yang dapat meningkatkan profitabilitas agar kinerja perbankan semakin baik.

Adapun yang dapat direkomendasikan adalah:

1. Untuk penelitian selanjutnya diharapkan menggunakan variabel yang lebih banyak tidak hanya variabel kinerja keuangan bank syariah tetapi juga variabel pendapatan, inflasi, tingkat bunga, dan investasi dimasukkan sebagai penentu tingkat ROA di Perbankan Syariah.

2. Bagi pengguna jasa keuangan perbankan khususnya perbankan syariah hendaknya dapat mempertimbangkan kinerja perbankan sebelum memutuskan pilihan pada salah satu perbankan syariah di Indonesia dengan memperhatikan rasio-rasio keuangan perbankan baik berupa variabel dalam penelitian ini maupun yang tidak termasuk dalam penelitian.

3. Bagi investor perlu memperhatikan laporan keuangan perbankan agar tingkat likuiditasnya selalu terjaga dengan baik, karena bagaimanapun tujuan utama dari investor yang menabung lebih banyak berorientasi pada laba.

4. Penelitian ini diharapkan dapat memberikan manfaat kepada investor maupun bagi bank untuk dapat membuat keputusan ekonomi yang berpengaruh terhadap profitabilitas perbankan yang disebabkan dan berkaitan dengan kinerja keuangan. 


\section{REFERENSI}

Annisa, H. Lestari. (2015). Faktor-Faktor Yang Mempengaruhi Profitabilitas Bank Syariah Yang Terdaftar Di Bursa Efek Indonesia. Jurnal Seminar Nasional Cendikiawan 2015, (ISSN: 2460-8696)

Dendawijaya, Lukman. (2003). Manajemen Perbankan (Edisi Kedua). Ghalia Indonesia.

Hakiim, N. (2018). Pengaruh Internal Capital Adequency Ratio (Car), Financing To Deposit Ratio (Fdr), Dan Biaya Operasional Per Pendapatan Operasional (Bopo) Dalam Peningkatan Profitabilitas Industri Bank Syariah Di Indonesia. Jurnal Mega Aktiva, 7(ISSN 2086-1974), 39-47.

Lemiyana, \& Litriani, E. (2016). Pengaruh Npf, Fdr, Bopo Terhadap Return on Asset (Roa) Pada Bank Umum Syariah. I-Economics, 2(1), 31-49.

Noor Rohman, S., \& Karsinah, K. (2016). Analisis Determinan Pangsa Pasar Bank Syariah dengan Kinerja Bank Syariah di Indonesia Periode 2011-2016. Economics Development Analysis Journal, 5(2), 135-142. https://doi.org/10.15294/edaj.v5i2.22026

Rahman, A. F, Rochmanika, R. (2012). Pengaruh pembiayaan Jual Beli, Pembiayaan Bagi Hasil terhadap Profitabilitas Bank Umum Syariah di Indonesia. Journal Ekonomi, Universitas Brawijaya, Malang.

Sinaga, Asmawarna. (2016). Analisis Pengaruh Tingkat Suku Bungan (Bi Rate), Bagi Hasil, Inflasi Dan Harga Emas Terhadap Perbankan Syariah Periode 2010-2015. Journal Analytica Islamica, 5(2), 315-341

Statistik Perbankan Syariah. (On-Line) In: www.ojk.go.id. Diunduh 16 Febuari 2020.

Suhartik, N., \& Kusumaningtias. (2013). Determinan Finaning to Deposit Ratio Perbankan Syariah di Indonesia. Jurnal Jurusan Manajemen, Fakultas Ekonomi Universitas Negri Surabaya.

Tifanny, T. A. (2018). Pengaruh Capital Adequacy Ratio (Car), Biaya Operasional Pada Pendapatan Operasional (Bopo), Financing To Deposit Ratio (Fdr), Sertifikat Bank Indonesia Syariah (Sbis), Dan Inflasi Terhadap Risiko Pembiayaan Bermasalah Pada Bank Umum Syariah Di Indonesia. Skripsi Universitas Negri Yogyakarta, 10(1), 279-288. https://doi.org/10.1542/peds.2006-2099 